\title{
Eficiência de fluridone no Controle de Plantas Aquáticas SUBMERSAS NO RESERVATÓRIO DE JUPIÁ ${ }^{1}$
}

\author{
Fluridone Efficacy for Control of Submersed Aquatic Weeds in the Jupiá Reservoir
}

\author{
MARCONDES, D.A.S. ${ }^{2}$, VELINI, E.D. ${ }^{3}$, MARTINS, D. ${ }^{3}$, TANAKA, R.H. ${ }^{4}$, CARVALHO, F.T. ${ }^{5}$, \\ CAVENAGHI, A.L. ${ }^{6}$ e BRONHARA, A.A. ${ }^{7}$
}

\begin{abstract}
RESUMO - O objetivo deste estudo foi avaliar a eficiência do herbicida fluridone no controle de plantas aquáticas submersas (Egeria densa, Egeria najas e Ceratophyllum demersum) que ocorrem no reservatório da Usina Hidrelétrica Eng. Souza Dias (Jupiá), região noroeste do Estado de São Paulo. A pesquisa, que consistiu de aplicações de fluridone, foi conduzida em lagoas marginais do rio Tietê, denominadas Flórida e Barrenta. As lagoas foram divididas em faixas, cada uma delas representando um tratamento. As faixas das lagoas receberam uma aplicação inicial de fluridone, procurando-se atingir a concentração de 20 ppb. As aplicações subseqüentes foram dimensionadas para recompor e/ou manter esta concentração, sendo realizadas sempre com o auxílio de uma barra de aplicação munida de três mangueiras, com pontas injetoras submersas na água, em três profundidades $(0,2,0,6$ e 1,2 m). O volume de aplicação foi mantido próximo a 541 ha $^{-1}$ de calda. Foram feitas avaliações visuais dos sintomas de fitointoxicação nas três espécies estudadas, assim como avaliação da biomassa. Nas condições da pesquisa, o fluridone controlou as macrófitas submersas Egeria najas e Egeria densa; quando cessou o efeito do fluridone, aconteceu a reinfestação de Egeria densa e Egeria najas; e não houve controle de Ceratophyllum demersum nem das espécies não-alvo, como Salvinia auriculata, Ipomoea spp., Merremia sp., Typha latifolia e Cyperus spp.
\end{abstract}

Palavras-chave: herbicida, macrófita aquática, Egeria densa, Egeria najas, Ceratophyllum demersum.

\begin{abstract}
The objective of this study was to evaluate the efficacy of the herbicide fluridone on the control of submersed aquatic weeds (Egeria densa Planch., Egeria najas Planch. and Ceratophyllum demersum), the major aquatic weeds in the reservoir of Eng ${ }^{\circ}$ Souza Dias (Jupiá) Hydroelecric Power Plant, Itapura, São Paulo. The experiment, consisted of fluridone applications and was carried out in bays of the Tietê River, called Flórida and Barrenta. The lakes were divided into zones, each considered a treatment. All treated zones in the lakes received an initial fluridone application to achieve the concentration of $20 \mathrm{ppb}$. The fluridone amount used in all the other applications was calculated to restore the $20 \mathrm{ppb}$ concentration. The applications were performed with a bar with three injection nozzles submersed at three different depths (0.2; 0.6 and 1.2 meter). The application volume was $54 \mathrm{l} / \mathrm{ha}$ in each operation. Visual evaluations of phytotoxicity symptoms on the three species studied and biomass evaluations were carried out. Under the conditions of this work, fluridone controlled the submersed aquatic plants Egeria najas and Egeria densa; Egeria densa and Egeria najas reinfested the area as the effect of fluridone ended; Ceratophyllum demersum and non-target plants, such as Salvinia auriculata, Ipomoea spp., Merremia sp., Typha latifolia, Cyperus spp., were not controlled.
\end{abstract}

Key words: herbicide, aquatic macrophyte, Egeria densa, Egeria najas, Ceratophyllum demersum.

\footnotetext{
Recebido para publicação em 20.9.2002 e na forma revisada em 30.10.2002.

2 Eng.-Agr., Dr., Companhia Energética de São Paulo, Al. Min. Rocha Azevedo, 25, 01410-900 São Paulo-SP. ${ }^{3}$ Prof. Assistente, Doutor, Dep. de Produção Vegetal da Faculdade de Ciências Agronômicas da Universidade Estadual Paulista - FCA/UNESP, Caixa Postal 237, 18603-970 Botucatu-SP. ${ }^{4}$ Eng.-Agr., M.S., Companhia Energética de São Paulo. ${ }^{5}$ Prof. Assistente Doutor da FEIS/UNESP. ${ }^{6}$ Eng.-Agr., Dr., Dep. de Produção Vegetal da FCA/UNESP. ${ }^{7}$ Eng.-Agr., Álvaro Alvares Abreu Silva Filho, 45, 13066-110 Campinas-SP.
} 


\section{INTRODUÇÃO}

O fato de ambientes hídricos tornarem-se infestados por plantas aquáticas é uma indicação de que a água apresenta um problema de difícil solução: o excesso de nutrientes, provenientes de fontes como o esgoto doméstico, a erosão de terras agrícolas, os resíduos industriais e a decomposição de plantas e de outros organismos (Patton \& Starnes, 1970).

Segundo Pitelli (1998), no Brasil, as plantas aquáticas representam grandes problemas em três ambientes alterados pelo homem: lagos e reservatórios eutrofizados próximos a centros urbanos; represas rurais e canais de irrigação e de drenagem; e grandes reservatórios de usinas hidrelétricas.

Poucas espécies submersas tornaram-se problemas em escala continental, ao contrário de algumas espécies flutuantes. Entretanto, localmente, elas podem representar grandes problemas. Várias espécies submersas têm ampla distribuição e, conseqüentemente, ampla tolerância às variações ambientais (Cook, 1990). Em corpos hídricos alterados, não é incomum uma espécie nativa desenvolver-se rapidamente, a ponto de tornar-se uma ameaça para a utilização da água.

O reservatório da Usina Hidrelétrica Eng. Souza Dias (Jupiá), pertencente à Companhia Energética de São Paulo (CESP), apresenta grandes populações de plantas aquáticas submersas, principalmente das espécies Egeria densa, Egeria najas e Ceratophyllum demersum. Estas plantas ocupam grandes extensões do reservatório, com acúmulos de matéria fresca de até $50 \mathrm{t} \mathrm{ha}^{-1}$ nos pontos de maior colonização, que correspondem às lagoas marginais situadas ao longo do leito do rio Tietê. No período chuvoso, as cheias deslocam massas de plantas em direção da usina, onde se acumulam nas grades de proteção das unidades geradoras, tornando obrigatória sua remoção, a fim de evitar o entupimento das grades.

Em diversos países, um dos produtos mais utilizados no controle de plantas aquáticas submersas é o fluridone, registrado nos Estados Unidos desde 1986 para o manejo seletivo de vegetação aquática em tanques, lagos, reservatórios, rios e canais de drenagem e de irrigação (Sepro, 1994). Burns et al. (1995) consideraram que o herbicida fluridone é uma ferramenta valiosa no manejo de plantas aquáticas, por possuir um perfil toxicológico seguro.

Segundo Netherland et al. (1993), a eficácia do fluridone é altamente dependente do tempo de exposição e da concentração do produto na água. Ao avaliar a eficácia de fluridone no controle de Egeria najas em uma represa, sem fluxo de água, Tanaka (2001) constatou que a manutenção da concentração do herbicida na água entre 3,39 e $23,65 \mathrm{ppb}$, por 87 dias, proporcionou controle superior a $99 \%$ e que a meia-vida do fluridone foi de 11,8 dias.

Os prejuízos provocados por estas espécies (Egeria densa, Egeria najas e Ceratophyllum demersum) e seu potencial de crescimento justificam o desenvolvimento de alternativas para o seu controle no Brasil. O objetivo deste estudo foi avaliar a eficiência do herbicida fluridone no controle de plantas submersas em duas lagoas marginais do reservatório de Jupiá, denominadas Flórida e Barrenta.

\section{MATERIAL E MÉTODOS}

O estudo foi desenvolvido no reservatório de Jupiá, no município de Itapura, região noroeste do Estado de São Paulo, em duas reentrâncias denominadas lagoas Flórida e Barrenta, com características diferentes entre si. A lagoa Flórida (com coordenadas geográficas: $20^{\circ} 40^{\prime} 30,9^{\prime \prime} \mathrm{S}$ e $51^{\circ} 22^{\prime} 28,0^{\prime \prime} \mathrm{W}$ ) possui 22,7 ha, com profundidade média de $2,80 \mathrm{~m}$, e foi dividida em cinco faixas, sendo quatro efetivamente tratadas (17,6 ha). A lagoa Barrenta (com coordenadas geográficas: $20^{\circ} 40^{\prime} 02,5$ ” S e $\left.51^{\circ} 20^{\prime} 10,1^{\prime \prime} \mathrm{W}\right)$ possui 41,9 ha, com profundidade média de $1,98 \mathrm{~m}$, e foi dividida em sete faixas, sendo cinco tratadas $(27,2$ ha) (Figura 1).

Nas Tabelas 1 e 2 são apresentadas as informações referentes à área e à profundidade das faixas das lagoas Flórida e Barrenta, respectivamente.

O herbicida utilizado foi o fluridone (1-metil-3-fenil-5-[3-(trifluorometil)-fenil]-4(1H)-piridinona), que é um composto sistêmico e tem como mecanismo de ação a inibição da síntese de carotenóides (Sprecher et al., 1998). A marca comercial utilizada foi Sonar AS, concentrado solúvel (480 g i.a. fluridone $\mathrm{L}^{-1}$ ). 


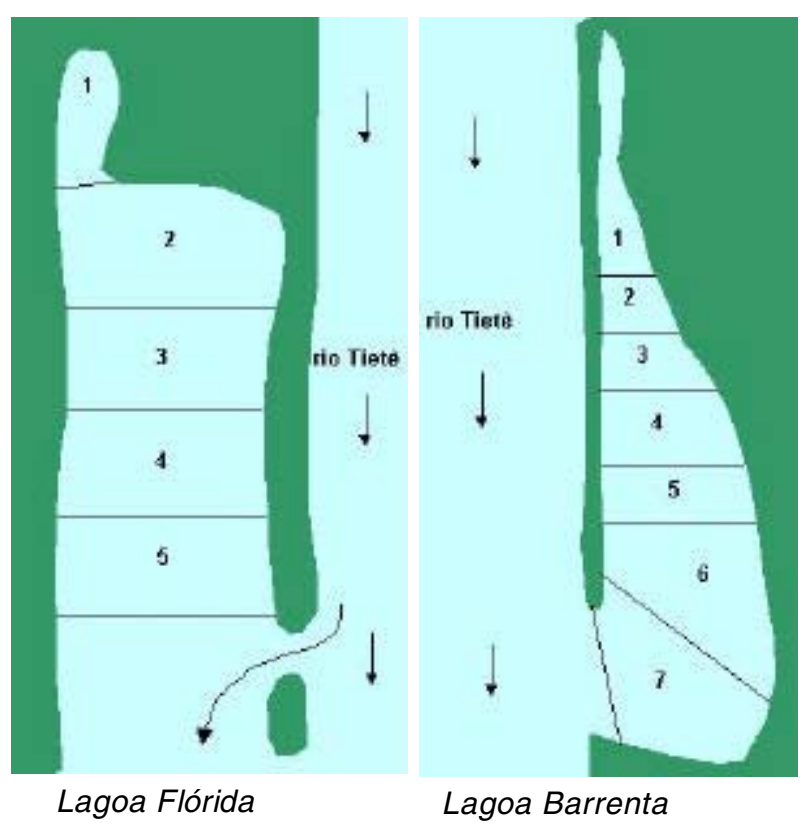

Figura 1 - Divisão das lagoas Flórida e Barrenta em faixas e os fluxos de água.

Tabela 1 - Área, profundidade e volume das faixas em que foi dividida a lagoa Flórida

\begin{tabular}{|c|c|c|c|}
\hline Faixa & Área (ha) & Volume $\left(\mathrm{m}^{3}\right)$ & Profundidade $(\mathrm{m})$ \\
\hline 1 & 1,80 & 30.495 & 1,69 \\
2 & 7,78 & 162.817 & 2,09 \\
3 & 4,94 & 167.726 & 3,40 \\
4 & 3,11 & 108.014 & 3,47 \\
5 & 5,07 & 177.590 & 3,50 \\
\hline Total & 22,71 & 646.642 & $-\cdot-$ \\
\hline
\end{tabular}

Tabela 2 - Área, profundidade e volume de água. Lagoa Barrenta

\begin{tabular}{|c|c|c|c|}
\hline Faixa & Área (ha) & Volume $\left(\mathrm{m}^{3}\right)$ & Profundidade $(\mathrm{m})$ \\
\hline 1 & 5,38 & 95.306 & 1,77 \\
2 & 4,92 & 104.886 & 2,13 \\
3 & 4,13 & 107.077 & 2,59 \\
4 & 7,43 & 136.900 & 1,84 \\
5 & 5,29 & 97.303 & 1,84 \\
6 & 7,40 & 136.238 & 1,84 \\
7 & 6,74 & 124.692 & 1,85 \\
\hline Total & 41,29 & 802.402 &.-- \\
\hline
\end{tabular}

As aplicações foram realizadas utilizandose um barco motorizado, ao qual foi acoplado um sistema de aplicação de herbicidas composto de motor a gasolina, bomba e barra de aplicação com três mangueiras com pontas injetoras, que ficavam submersas na água. As mangueiras apresentavam comprimentos diferenciados, para que o herbicida fosse injetado na coluna d'água em três profundidades $(0,2,0,6$ e 1,2 m). Durante a aplicação, o barco deslocou-se a $8 \mathrm{~km} / \mathrm{h}$, controlado com auxílio de um aparelho de GPS. A vazão total nas três pontas injetoras foi de $8 \mathrm{~L} \mathrm{minuto}^{-1}$, o que proporcionou volume de aplicação de 541 ha $^{-1}$ de calda.

Para determinar a concentração de fluridone em água, utilizou-se o método cromatográfico desenvolvido e validado no laboratório de Matologia da Faculdade de Ciências Agronômicas da UNESP, campus de Botucatu/ SP. O método apresenta recuperação média de $94,9 \%$, incerteza inferior a $2 \%$ para a faixa de concentrações testada e limite de determinação de 50 ng $\mathrm{L}^{-1}$.

As faixas das lagoas receberam uma aplicação inicial de herbicida, com a qual se procurou chegar a uma concentração de $20 \mathrm{ppb}$ do ingrediente ativo na água. As aplicações subseqüentes de fluridone foram dimensionadas para recompor e/ou manter esta concentração. Foi considerada como testemunha uma lagoa localizada a montante da área experimental.

As épocas das aplicações na lagoa Flórida foram: $1^{\mathrm{a}}$ : 28/10/1999; $2^{\mathrm{a}}$ : 07/11/1999; $3^{\mathrm{a}}$ : 18/11/1999; 4a: 01/12/1999; 5a (1 ${ }^{\text {a }}$ metade): 21/12/1999, (2 $2^{\text {a }}$ metade): 10/01/2000; 6: 25/ 01/2000; 7a: 15/02/2000. Na lagoa Barrenta, as aplicações foram realizadas nas seguintes datas: 1a: 27/10/1999; 2a: 06/11/1999; 3a 17/11/1999; 4a: 01/12/1999; 5: (1 ${ }^{\mathrm{a}}$ metade): 22/12/1999, (2 $2^{\mathrm{a}}$ metade): 11/01/2000; 6ª $25 /$ 01/2000; 7ㄹ: 15/02/2000.

Nas Tabelas 3 e 4 são apresentadas as quantidades de produto comercial utilizadas no tratamento de cada faixa a cada aplicação para se atingir a concentração desejada nas lagoas Flórida e Barrenta, respectivamente.

As espécies de plantas-alvo foram Egeria densa, Egeria najas e Ceratophyllum demersum. Na época do estudo as plantas encontravam-se em pleno desenvolvimento, ocupando toda a coluna de água.

As avaliações da eficácia de controle das plantas-alvo consistiram de observações 
visuais dos sintomas de intoxicação nas plantas-alvo e não-alvo, além de avaliações de biomassa. As avaliações visuais foram efetuadas em todas as ocasiões em que foram feitas aplicações e amostragens de água, até maio de 2000. A avaliação de biomassa foi realizada 12 meses após o início da aplicação, com auxílio de um equipamento construído para esse fim.

Para a comparação dos valores de biomassa, foram adotados procedimentos nãoparamétricos. Os valores de biomassa presentes em cada faixa foram comparados com os da lagoa testemunha, com auxílio do teste "T" a $5 \%$ de probabilidade.

\section{RESULTADOS E DISCUSSÃO}

\section{Lagoa Flórida}

Na Tabela 5 encontram-se as informações referentes às médias das concentrações máximas e mínimas, além das concentrações médias de fluridone durante o período de controle (final estabelecido em 15 dias após a última aplicação).
Na Figura 2 encontram-se as informações de concentrações referentes às faixas de 1 a 5 da lagoa Flórida. Os dados evidenciam que, durante o período com aplicações, houve grande similaridade entre as concentrações encontradas nas faixas 2, 3 e 4 . Valores um pouco superiores ou inferiores foram encontrados nas faixas 1 e 5 , respectivamente.

Os valores médios para as concentrações máximas e mínimas, além das concentrações médias para todo o período experimental, também indicaram grande similaridade entre as faixas 2, 3 e 4 . Valores médios superiores foram encontrados na faixa 1 , e valores médios inferiores aos das três faixas centrais foram observados na faixa 5 .

Dez dias após o início das aplicações foram verificados sintomas típicos de intoxicação de fluridone nas três espécies de plantas submersas predominantes no reservatório. Ceratophyllum demersum foi a que apresentou descoloração mais acentuada, conforme descrito por Sprecher et al. (1998). Os sintomas mostraram-se mais intensos na faixa 1 , mas estiveram presentes em todas as faixas, incluindo a 5, sem tratamento.

Tabela 3 - Volumes de fluridone aplicados nas diferentes faixas da lagoa Flórida a cada aplicação (em litros do produto comercial)

\begin{tabular}{|c|c|c|c|c|c|c|c|c|}
\hline \multirow{2}{*}{ Faixa } & \multicolumn{8}{|c|}{ Aplicação } \\
\hline & 1 & 2 & 3 & 4 & 5 & 6 & 7 & Total \\
\hline 1 & 1,29 & 1,09 & 0,75 & 0,93 & 0,73 & 1,08 & 0,96 & 6,83 \\
\hline 2 & 6,89 & 5,80 & 4,11 & 5,30 & 5,96 & 7,20 & 6,74 & 42,00 \\
\hline 3 & 7,10 & 6,62 & 4,98 & 6,26 & 6,40 & 6,68 & 6,38 & 44,42 \\
\hline 4 & 4,57 & 3,96 & 3,04 & 3,80 & 2,92 & 3,49 & 3,41 & 25,19 \\
\hline Total & 19,85 & 17,47 & 12,88 & 16,29 & 16,01 & 18,45 & 17,49 & 118,44 \\
\hline
\end{tabular}

Tabela 4 - Volumes de fluridone aplicados nas diferentes faixas da lagoa Barrenta a cada aplicação (em litros do produto comercial)

\begin{tabular}{|c|c|c|c|c|c|c|c|c|}
\hline \multirow{2}{*}{ Faixa } & \multicolumn{8}{|c|}{ Aplicação } \\
\hline & 1 & 2 & 3 & 4 & 5 & 6 & 7 & Total \\
\hline 1 & 4,03 & 3,36 & 1,78 & 2,61 & 0,78 & 0,91 & 2,80 & 16,27 \\
\hline 2 & 4,44 & 3,66 & 2,42 & 3,48 & 1,16 & 1,13 & 3,76 & 20,05 \\
\hline 3 & 4,53 & 3,82 & 2,44 & 3,88 & 1,34 & 1,23 & 4,61 & 21,85 \\
\hline 4 & 5,79 & 4,31 & 2,92 & 4,43 & 2,07 & 2,31 & 5,39 & 27,22 \\
\hline 5 & 4,12 & 3,41 & 2,21 & 3,08 & 1,99 & 4,04 & 5,45 & 24,30 \\
\hline Total & 22,91 & 18,56 & 11,77 & 17,48 & 7,34 & 9,62 & 22,01 & 109,69 \\
\hline
\end{tabular}


Tabela 5 - Valores médios para as concentrações (ppb) máximas, mínimas e médias de fluridone (i.a.) em cada faixa experimental durante o período de controle. Lagoa Flórida

\begin{tabular}{|c|c|c|c|}
\hline \multirow{2}{*}{ Faixa } & \multicolumn{3}{|c|}{ Concentração de fluridone - ppb } \\
\cline { 2 - 3 } & \multicolumn{2}{|c|}{ Média para valor } & \multirow{2}{*}{ Média } \\
\cline { 2 - 3 } & Máximo & Mínimo & \\
\hline 1 & 26,22 & 5,06 & 12,37 \\
2 & 20,44 & 3,36 & 9,73 \\
3 & 20,86 & 2,98 & 9,55 \\
4 & 22,33 & 2,79 & 9,66 \\
5 & 15,77 & 2,60 & 7,69 \\
\hline
\end{tabular}

Nas avaliações posteriores, $21,34,50,54$, 74 e 89 dias após o início das aplicações, observou-se a intensificação do processo de decomposição de Egeria densa e Egeria najas, com grande redução das duas espécies, sobretudo nas duas últimas avaliações. Não houve evolução da intoxicação do Ceratophyllum demersum. Todas as novas brotações de Egeria densa, Egeria najas e Ceratophyllum demersum presentes nas faixas de 1 a 5 apresentavamse descoloridas.
Observou-se grande redução da infestação de Egeria densa e Egeria najas nas faixas de 1 a 4 . Menores níveis de controle destas espécies foram observados na faixa 5 . Os niveis máximos de controle de Egeria densa e Egeria najas foram observados a partir de janeiro de 2000 e mantiveram-se estáveis, nas faixas de 1 a 4 , até maio/2000.

Ceratophyllum demersum foi a espécie de controle mais difícil. Embora os sintomas de intoxicação tenham sido detectados nas plantas dessas espécies em todas as avaliações realizadas até 23/03/2000, em nenhum momento observaram-se reduções populacionais, indicando a ineficiência do fluridone, no controle desta espécie, nas concentrações estudadas.

Foram observados sintomas de intoxicação em plantas de Salvinia sp., Typha latifolia e Cyperus sp. Algumas plantas de Eichhornia azurea também apresentaram descoloração de folhas, porém os sintomas foram menos intensos. Esses sintomas estiveram presentes durante o período com aplicação de fluridone, mas houve recuperação das plantas nas fases posteriores.

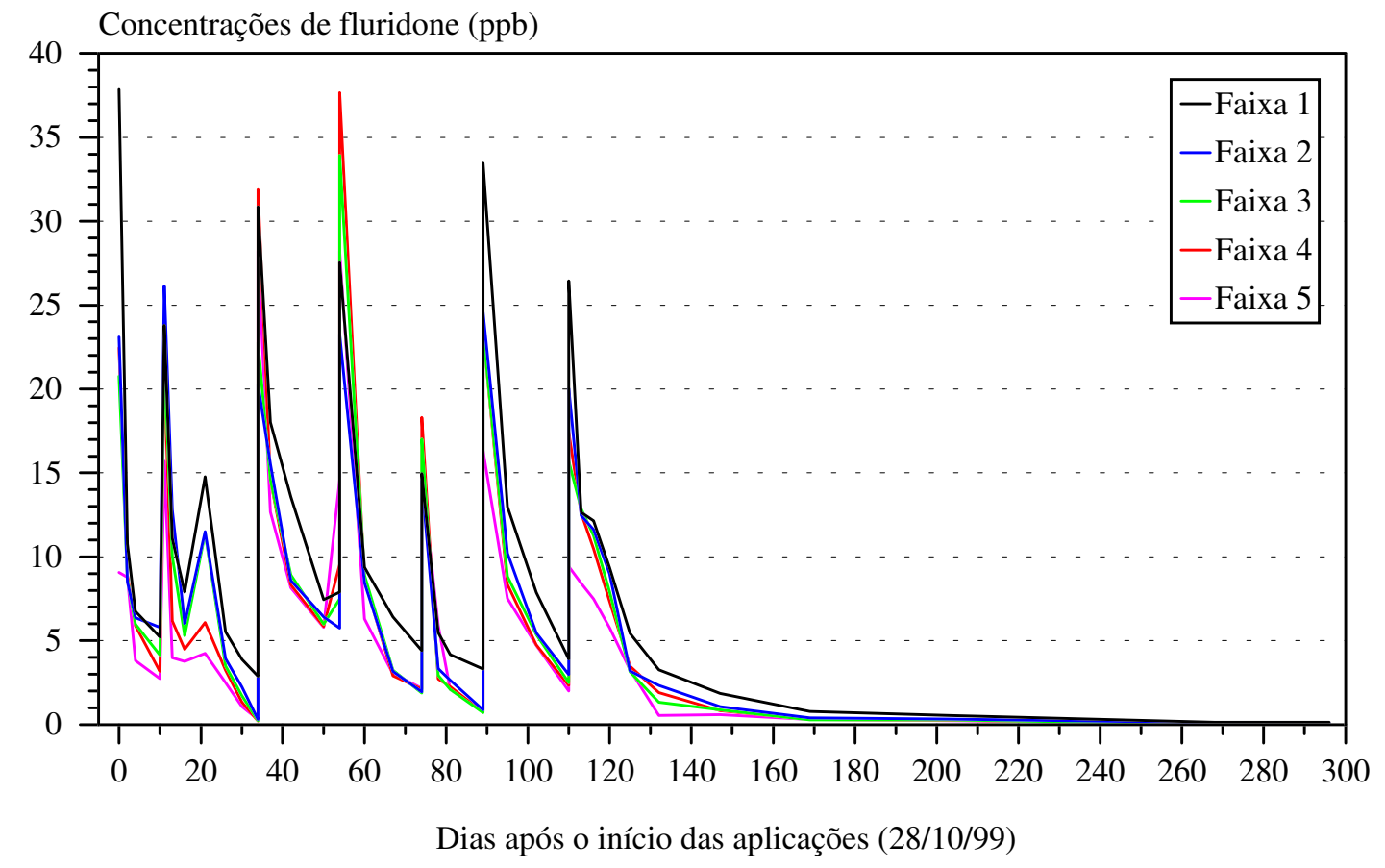

Figura 2 - Concentrações de fluridone na água das faixas de 1 a 5 da lagoa Flórida. 
Nas Tabelas 6 e 7 são apresentados os valores de biomassa encontrados na avaliação realizada 12 meses após o início do estudo e as porcentagens de controle de cada espécie, respectivamente.

Reduções significativas de biomassa de Egeria densa associadas a porcentagens de controle iguais ou superiores a 96,9\% foram verificadas nas faixas 1 e 4 da lagoa Flórida. $\mathrm{Na}$ faixa 5, embora a redução de biomassa desta espécie tenha sido de $68,5 \%$, não houve diferenças significativas entre os valores médios encontrados nesta faixa e os verificados na lagoa testemunha.

Para Egeria najas, reduções significativas de biomassa associadas a porcentagens de controle iguais ou superiores a $98,2 \%$ estiveram presentes em todas as faixas da lagoa Flórida, incluindo-se a faixa 5. Para esta espécie, concentrações menores de fluridone presentes na faixa 5 foram suficientes para proporcionar elevados niveis de controle.

Quanto a Ceratophyllum demersum, todas as faixas da lagoa Flórida apresentaram acúmulos de biomassa fresca superiores aos verificados na lagoa testemunha. Em razão da grande variabilidade dos dados obtidos para esta espécie, as diferenças entre os valores das faixas e os referentes à testemunha não foram significativas.

Os resultados obtidos na lagoa Flórida demonstraram que a exposição contínua a concentrações de fluridone, entre $26,2 \mathrm{ppb}$ (média das concentrações máximas) e 2,79 ppb (média das concentrações mínimas), por um período de 130 dias, reduziu significativamente a biomassa e possibilitou niveis de controle de 96,9 a $100 \%$ para Egeria densa. Para Egeria najas, a manutenção das concentrações de fluridone entre 26,2 e 2,60 ppb, pelo mesmo período, reduziu significativamente a biomassa e possibilitou niveis de controle de 96,9 a $100 \%$. Não foi possivel obter controle de Ceratophyllum demersum.

\section{Lagoa Barrenta}

Na Figura 3 são apresentadas as informações de concentrações referentes às faixas de 1 a 7 na lagoa Barrenta. Durante o período com aplicações, houve grande similaridade entre as concentrações encontradas nas faixas 2 e 3. Níveis de concentração inferiores aos de todas as demais faixas com tratamento foram observados na faixa 5 . Nas faixas 6 e, sobretudo, na 7, as concentrações de fluridone foram muito inferiores às observadas em todas as faixas com tratamento.

Tabela 7 - Porcentagens de controle de Egeria densa, Egeria najas e Ceratophyllum demersum na avaliação realizada de 9 a 18 de agosto de 2000. Lagoa Flórida

\begin{tabular}{|c|c|c|c|c|}
\hline \multirow{2}{*}{ Faixa } & \multicolumn{3}{|c|}{$\%$ de controle de Egeria } & \multirow{2}{*}{$\begin{array}{c}\text { \% de controle de } \\
\text { C. demersum }\end{array}$} \\
\cline { 2 - 4 } & $\begin{array}{c}\text { Egeria } \\
\text { densa }\end{array}$ & $\begin{array}{c}\text { Egeria } \\
\text { najas }\end{array}$ & Total & \\
\hline 1 & 96,9 & 100,0 & 98,3 & - \\
2 & 98,4 & 99,7 & 99,0 & - \\
3 & 100,0 & 98,5 & 99,3 & - \\
4 & 100,0 & 98,2 & 99,2 & - \\
5 & 68,5 & 96,9 & 81,0 & - \\
\hline
\end{tabular}

Tabela 6 - Biomassa fresca $\left(\mathrm{kg} \mathrm{ha}^{-1}\right)$ e teores médios de umidade de Egeria densa, Egeria najas e Ceratophyllum demersum na avaliação realizada de 9 a 18/08/2000. Lagoa Flórida

\begin{tabular}{|c|c|c|c|c|}
\hline \multirow{2}{*}{ Faixa } & \multicolumn{3}{|c|}{ Biomassa de Egeria } & \multirow{2}{*}{ Biomassa de $C$. demersum } \\
\hline & Egeria densa & E. najas & Total & \\
\hline 1 & $268,4 \quad b$ & $0,0 \quad b$ & $268,4 \quad b$ & $16.042,8 \quad \mathrm{a}$ \\
\hline 2 & $139,5 \mathrm{~b}$ & $18,9 \quad b$ & $158,4 \quad b$ & $17.803,0 \quad \mathrm{a}$ \\
\hline 3 & $0,0 \quad \mathrm{~b}$ & $100,4 \quad b$ & $100,4 \quad b$ & $20.700,4 \quad a$ \\
\hline 4 & $0,0 \quad b$ & $123,4 \quad b$ & $123,4 \quad b$ & $21.256,2 \quad \mathrm{a}$ \\
\hline 5 & $2.726,4 \mathrm{ab}$ & $211,9 \quad b$ & $2.938,4 \quad b$ & $28.633,5 \quad \mathrm{a}$ \\
\hline Testemunha & $8.660,3 \quad \mathrm{a}$ & $6.770,5 \quad \mathrm{a}$ & $15.430,8 \quad \mathrm{a}$ & $6.923,3 \quad \mathrm{a}$ \\
\hline Teores de água (\%) & 93,7 & 94,5 & 94,1 & 93,1 \\
\hline
\end{tabular}




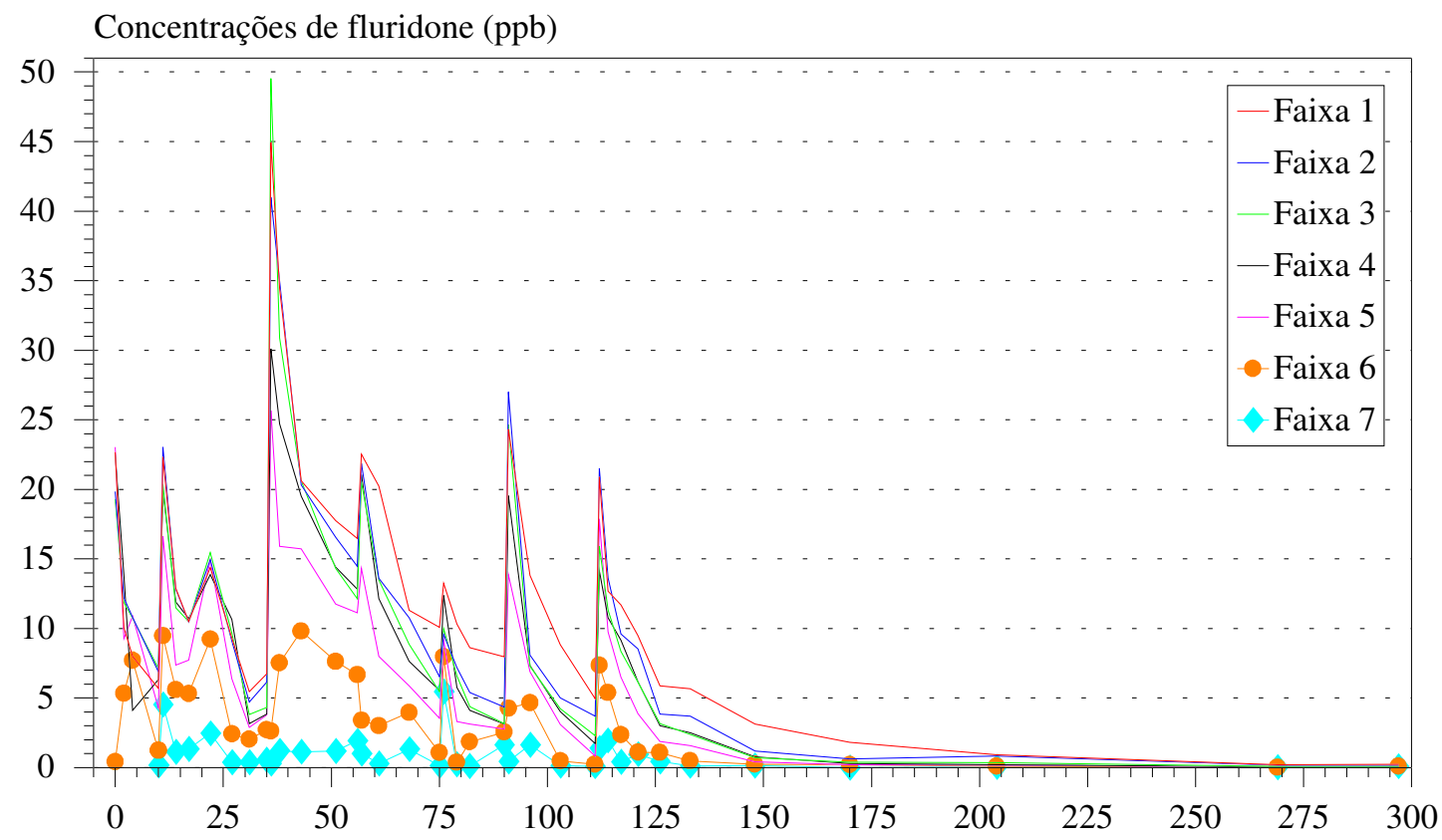

Dias após o início das aplicações (27/10/99)

Figura 3 - Concentrações de fluridone nas faixas de 1 a 7 da lagoa Barrenta durante o período de avaliação do experimento.

Na Tabela 8 são apresentadas as informações referentes às médias das concentrações máximas e mínimas, além das concentrações médias em todas as faixas, durante todo o período de controle (com final estabelecido em 15 dias após a última aplicação). Observa-se que, em termos médios, houve redução de aproximadamente $1 \mathrm{ppb}$ por faixa com o deslocamento da faixa 1 até a faixa 4 . A concentração média da faixa 5 foi $2,06 \mathrm{ppb}$ inferior à média da faixa 4 . As diferenças entre as concentrações médias das faixas 5 e 6 e 6 e 7 foram de 4,96 e $2,95 \mathrm{ppb}$, respectivamente. Esses resultados indicam maior uniformidade das concentrações nas faixas de 1 a 4 .

Nas avaliações visuais realizadas aos 10 , $21,34,50,54,74$ e 89 dias após o início das aplicações, observou-se grande redução de Egeria densa nas faixas de 1 a 5. Niveis intermediários de controle foram verificados na faixa 6 . Na faixa 7 não foram constatadas reduções das espécies em estudo.

Os níveis máximos de controle de Egeria densa, a espécie predominante, foram observados a partir de janeiro de 2000 e mantiveram-se estáveis, nas faixas de 1 a 5, até 18/05/2000, quando se iniciou a constituição de novas populações desta espécie. Ceratophyllum demersum novamente mostrou ser a espécie de controle mais difícil. Em nenhum momento foram observadas reduções visualmente detectáveis desta espécie, indicando a ineficiência das concentrações de fluridone.

Tabela 8 - Valores médios para as concentrações (ppb) máximas, mínimas e médias de fluridone (i.a.) em cada faixa experimental durante o período de controle. Lagoa Barrenta

\begin{tabular}{|c|c|c|c|}
\hline \multirow{2}{*}{ Faixa } & \multicolumn{3}{|c|}{ Concentração de fluridone - ppb } \\
\cline { 2 - 3 } & \multicolumn{2}{|c|}{ Média dos valor } & \multirow{2}{*}{ Média } \\
\cline { 2 - 3 } & Máximo & Mínimo & \\
\hline 1 & 23,17 & 7,77 & 14,26 \\
2 & 22,35 & 6,43 & 13,10 \\
3 & 21,97 & 5,54 & 12,21 \\
4 & 19,20 & 4,98 & 11,07 \\
5 & 16,93 & 3,96 & 9,01 \\
6 & 7,51 & 1,13 & 4,06 \\
7 & 2,43 & 0,22 & 1,11 \\
\hline
\end{tabular}


Nas Tabelas 9 e 10 são apresentados os valores de biomassa encontrados na avaliação realizada 12 meses após o início do estudo e as porcentagens de controle de cada espécie, respectivamente.

Reduções significativas de biomassa de Egeria densa associadas a porcentagens de controle iguais ou superiores a $67,5 \%$ foram verificadas nas faixas de 1 a 5 , da lagoa Barrenta. Na faixa 6, embora a redução de biomassa de Egeria densa tenha sido de 48,5\%, não houve diferença significativa entre os valores encontrados nesta faixa e os verificados na faixa 7 , tomada como referencial para cálculo dos níveis de controle.

Em razão da pequena participação da Egeria najas na comunidade de plantas submersas na lagoa Barrenta, não foram analisados os dados de biomassa desta espécie e os dados referentes ao acúmulo total de biomassa das duas espécies de Egeria.

No caso de Ceratophyllum demersum, a grande variabilidade dos dados obtidos impossibilitou a obtenção de comparações significativas e, conseqüentemente, o estabelecimento de conclusões que indicassem qualquer tipo de resposta desta espécie ao fluridone.

Comparando-se ao controle obtido na lagoa Flórida, os menores níveis de eficiência encontrados na lagoa Barrenta, mesmo com concentrações similares de fluridone, provavelmente tiveram como principal justificativa o maior nível inicial de infestação nesta última lagoa.
Altos níveis de infestação, principalmente quando parte das plantas está fora da coluna de água, condicionam menores taxas de crescimento às plantas. A ação do fluridone ocorre somente em tecidos jovens, havendo limitação à ação do herbicida quando as plantas se encontram estressadas ou apresentam crescimento lento.

Tabela 10 - Porcentagens de controle de Egeria densa, Egeria najas e Ceratophyllum demersum na avaliação realizada de 9 a 18 de agosto de 2000. Lagoa Barrenta

\begin{tabular}{|c|c|c|c|c|}
\hline \multirow{2}{*}{ Faixa } & \multicolumn{2}{|c|}{$\%$ de controle de Egeria } & \multirow{2}{*}{$\begin{array}{c}\text { o de controle de } \\
\text { C. demersum }\end{array}$} \\
\cline { 2 - 4 } & $\begin{array}{c}\text { Egeria } \\
\text { densa }\end{array}$ & $\begin{array}{c}\text { Egeria } \\
\text { najas }\end{array}$ & Total & \\
\hline 1 & 73,1 & - & - & 0,0 \\
2 & 79,0 & - & - & 0,0 \\
3 & 67,8 & - & - & 0,0 \\
4 & 74,4 & - & - & 0,0 \\
5 & 67,5 & - & - & 0,0 \\
6 & - & - & - & 0,0 \\
\hline
\end{tabular}

Nas condições em que foi desenvolvido o presente trabalho, pode-se concluir que: a exposição contínua a concentrações de fluridone entre 2,79 e 26,2 ppb por um período de 130 dias, na lagoa Flórida, reduziu significativamente a biomassa e permitiu atingir niveis de controle de Egeria densa e Egeria najas superiores a 98,3\%; a exposição contínua a concentrações de fluridone entre 4,0 e 23,2 ppb por um período de 122 dias, na lagoa Barrenta,

Tabela 9 - Biomassa fresca $\left(\mathrm{kg} \mathrm{ha}^{-1}\right)$ e teores médios de umidade de Egeria densa, Egeria najas e Ceratophyllum demersum na avaliação realizada de 9 a 18 de agosto de 2000. Lagoa Barrenta

\begin{tabular}{|c|c|c|c|c|}
\hline \multirow{2}{*}{ Faixa } & \multicolumn{3}{|c|}{ Biomassa de Egeria } & \multirow{2}{*}{ Biomassa de $C$. demersum } \\
\hline & Egeria densa & E. najas $^{1 /}$ & Total $^{1 /}$ & \\
\hline 1 & $4.716,5 \quad b$ & 0,0 & $4.716,5$ & $4.153,3$ a \\
\hline 2 & $3.684,9 \quad b$ & 80,0 & $3.764,9$ & $9.931,2 \mathrm{a}$ \\
\hline 3 & $5.646,3 \quad b$ & 375,3 & $6.021,6$ & $5.361,0 \quad \mathrm{a}$ \\
\hline 4 & $4.492,1 \quad b$ & 276,6 & $4.768,7$ & $5.221,3 \mathrm{a}$ \\
\hline 5 & $5.696,1 \quad b$ & 983,1 & $6.679,2$ & $12.351,6 \mathrm{a}$ \\
\hline 6 & $9.029,8 \mathrm{ab}$ & 104,0 & $9.133,8$ & 436,0 a \\
\hline 7 & $17.548,1 \quad \mathrm{a}$ & 0,0 & $17.548,1$ & 21,9 a \\
\hline Testemunha & $8.660,3$ & $6.770,5$ & $15.430,8$ & $6.923,3$ \\
\hline Teores de água (\%) & 93,7 & 93,6 & 93,7 & 94,0 \\
\hline
\end{tabular}

${ }^{1 /}$ Dados não analisados estatisticamente ou não incluídos nas análises. 
reduziu significativamente a biomassa e permitiu atingir níveis de controle de Egeria densa superiores a $67,8 \%$; quando cessou o efeito do fluridone, ocorreu a recolonização do ambiente por Egeria densa e Egeria najas; e nas concentrações testadas, o fluridone não possibilitou o controle da Ceratophyllum demersum nem produziu efeito adverso sobre populações de espécies não-alvo, como Salvinia auriculata, Ipomoea fistulosa, Merremia sp., Typha latifolia e Cyperus spp.

\section{LITERATURA CITADA}

BURNS, A. et al. The use of sonar as a renovative tool to restore aquatic ecossystems. Lake Reserv. Manag., v. 11, n. 2, p. 122, 1995.

COOK, C. D. K. Origin, autoecology, and spread of the world's most troublesome aquatic weeds. In: PIETERSE, A. H., MURPHY, K. J. Aquatic weeds - the ecology and management of nuisance aquatic vegetation. New York: Oxford University Press, 1990. p. 31-38.
NETHERLAND, M. D.; GETSINGER, K. D.; TURNER, E. G. Fluridone concentration and exposure time requirements for control of Eurasian watermilfoil and hydrilla. J. Aquat. Plant Manag., v. 31, p. 189-194, 1993.

PATTON, V. D.; STARNES, W. E. Aquatic weeds and water pollution. Hyacinth Control Journal, v. 8, n. 2, p. 48-49, 1970.

PITELLI, R. A. Macrófitas aquáticas no Brasil, na condição de problemáticas. In: WORKSHOP CONTROLE DE PLANTAS AQUÁTICAS, 1998, Brasília. Resumos... Brasília: Instituto Brasileiro de Meio Ambiente e dos Recursos Naturais Renováveis, 1998. p. 12-15.

SEPRO CORPORATION. Sonar - An effective herbicide that poses negligible risk to human health and the environment. 1994. $8 \mathrm{p}$.

TANAKA, R. H. Eficácia de fluridone para o controle de Egeria spp. em caixas d'água e em represa de pequeno porte sem fluxo de água. 2001. $51 \mathrm{f}$. Dissertação (Mestrado em Agronomia/Agricultura) - Universidade Estadual Paulista, Botucatu. 2001. 